\title{
Ligustrazine-induced microRNA-16-5p inhibition alleviates preeclampsia through IGF-2
}

\author{
Yuan Yuan ${ }^{1, *}$, Ling Zhao ${ }^{2, *}$, Xiaoying Wang ${ }^{1}$, Feng $\operatorname{Lian}^{3}$ and Yan Cai ${ }^{1}$ \\ ${ }^{1}$ Department of Obstetrics, The Fourth Affiliated Hospital of Harbin Medical University, Harbin, China, ${ }^{2}$ The Second \\ Department of Respiratory, Harbin Medical University Cancer Hospital, Harbin, China and ${ }^{3}$ The Third Department \\ of Orthopaedics, The Fourth Affiliated Hospital of Harbin Medical University, Harbin, China
}

Correspondence should be addressed to Y Cai; Email: caiyan650318@163.com

*(Y Yuan and L Zhao contributed equally to this work)

\begin{abstract}
Preeclampsia (PE), a serious complication of pregnancy, is associated with abnormal trophoblast cell differentiation and autophagy. Herein, we investigated the molecular mechanism underlying the function of ligustrazine (2,3,5,6-tetramethylpyrazine, TMP), a constituent of the traditional Chinese plant medicine Ligusticum wallichii, in PE. Lipopolysaccharide (LPS) was applied to induce a PE rat model, followed by tail vein injection of TMP or lentiviral vector overexpressing microRNA-16-5p (miR-16-5p). Human trophoblast cell line JEG3 was cultured in vitro to construct a PE cell model, followed by $t$ he treatment with different concentrations of TMP, miR-16-5p mimic/inhibitor, or shRNA (shRNA) against insulin growth factor-2 (IGF-2) (sh-IGF-2). Formation of autophagosomes and autophagy-related proteins were then examined. Cell counting kit-8 (CCK-8) and Transwell assays were applied to measure trophoblast cell viability and migration. The binding affinity between miR-16-5p and IGF-2 was verified by dual luciferase report assay. After TMP treatment, autophagosome formation was reduced in trophoblast cells of placental tissue of PE rats, along with downregulation of autophagy-related proteins Light Chain 3 (LC3)-II/LC3-I, Beclin1 (BECN1), and SQSTM1. Moreover, TMP repressed JEG3 cell autophagy, promoted viability and migration concentration-responsively. MiR-16-5p was upregulated in PE, and TMP inhibited miR-16-5p expression. Besides, miR-16-5p downregulated IGF-2 expression to promote cell autophagy and inhibit the viability and migration of JEG3 cells. Further, in vivo experiments validated that TMP impeded PE progression in rats by regulating the miR-16-5p/IGF-2 axis. In summary, TMP inhibits trophoblast cell autophagy and promotes its viability and migration in PE rat model through regulating the miR-16-5p/IGF-2 axis.
\end{abstract}

Reproduction (2020) 160 905-917

\section{Introduction}

Preeclampsia (PE) is a frequent complication of pregnancy, which arises in the placenta and results in a wide array of maternal and fetal disorders (Redman \& Sargent 2005). According to the World Health Organization, $10 \%$ of pregnant women are diagnosed as having PE, and PE accounts for one-seventh of maternal deaths in China, which is equivalent to a incidence rate of 5\% (Say et al. 2014, Liang et al. 2019, Yang et al. 2020). PE is a pregnancy complication mainly occurring after 20 weeks of gestation, which is characterized by maternal hypertension and proteinuria (Phillips et al. 2020, Rozas-Villanueva et al. 2020). PE usually first manifests with hypertension followed by proteinuria in the third trimester, and the pathogenesis and impact on both mother and fetus make it a tremendously challenging condition (Rana et al. 2019). Previous research links PE to insufficient extravillous cytotrophoblast invasion and aberrantly excessive apoptosis in the placental trophoblast cells (Leach et al. 2002). Thus, the abnormal interplay of trophoblast and decidual-membrane is a major cause underlying PE (Vento-Tormo et al. 2018). Notably, traditional Chinese medicine (TCM) such as the herb Uncaria rhynchophylla has been widely applied for PE in China (Wang et al. 2018).

Ligustrazine (2,3,5,6-tetramethylpyrazine, TMP) is extracted from a traditional Chinese medicine Ligusticum wallichii, which has been proven to alleviate microcirculatory dysfunction and lung injury (Zhang \& Dang 2006). A prior study has suggested that TMP injections led to remarkable therapeutic effects on pregnancy-induced hypertension through repressing fibrinolysis and enhancing microcirculation (Wang \& Zhao 2003). Moreover, TMP administration attenuates placental endoplasmic reticulum stress in $P E$ rats (Gu et al. 2019). However, the molecular mechanisms underlying the pharmacological actions of TMP remain uncharacterized. Recent microRNA (miRNA) profiling studies have implicated the potential use of miRNAs 
as diagnostic and prognostic indicators in pregnancy complications, including PE (Choi et al. 2013). MiRNAs represent a series of noncoding 21- to 25-nucleotide RNAs which can inversely modulate gene expression posttranscriptionly (Wang et al. 2012a). Interestingly, microRNA-16 (miR-16) is expressed in the placental tissue and can modulate placental cell survival and development pathways (Maccani et al. 2011). A prior study by Wang et al. has pointed out the involvement of miR-16 in the pathogenesis of PE (Wang et al. 2012b), which sheds some light on the potential role of miR-16 in the clinical setting of PE. In this study, an initial bioinformatics analysis predicted the targeting relationship between miR-16-5p and insulin-like growth factor 2 (IGF-2). Previous work has shown IGF-2 to have a pivotal role in fetal development, and its abnormal expression is linked with maternal blood pressure dysfunction during pregnancy (Bozadjieva 2011). Previous work has shown an association between IGF-2 expression and $\mathrm{PE}$, yet the underlying mechanism needs further study (Jung et al. 2019). We thus predicted that TMP would affect PE progression in rats by regulating the miR-16-5p/IGF-2 axis. Therefore, we aimed in this study to test this hypothesized mechanism of the miR-16-5p/ IGF-2 axis underlying the pharmacological actions of TMP in a PE rat model.

\section{Materials and methods}

\section{Ethics statement}

The study was conducted under the approval of the ethics committee of the Fourth Affiliated Hospital of Harbin Medical University. All animal experiments were performed in strict accordance with the Guide for the Care and Use of Laboratory Animals of the National Institutes of Health.

\section{Experimental animals}

Healthy clean grade female Sprague Dawley (SD) rats (200$250 \mathrm{~g})$ and male SD rats (250-300 g) of 8-10 weeks old were purchased from Experimental Animal Center of The Secondary Military Medical University (SCXK (Hu)-2013-0016) All rats were routinely housed in an SPF environment for 1 week's acclimation. For breeding, female rats and male rats were housed in the same constant temperature cages at a gender ratio of $2: 1$. Cohabitation time was from 16:00 to $08: 00 \mathrm{~h}$ the next day. After separating the rats, the vaginal plugs were examined, and vaginal smears were taken to observe sperm and epithelial cells. If sperm were present on the smear, that day was considered the first day of rat pregnancy.

Pregnant rats were randomly classified into the blank group $(n=10$, from the 7 th day to the 18th day of pregnancy, physiological saline was injected through the tail vein at a dose of $1.0 \mu \mathrm{g} / \mathrm{kg} /$ day) or subjected to lipopolysaccharides (LPS) treatment ( $n=80$, from the 7 th day to the 18th day of pregnancy, the LPS solution (L-2880, Sigma) was injected through the tail vein at a dose of $20 \mu \mathrm{g} / \mathrm{kg} /$ day) ( $\mathrm{Li}$ et al. 2018). From the 3rd day of pregnancy, a BP-2010 A automatic noninvasive blood pressure monitor (Softron Co., Beijing, China) was used to monitor the arterial blood pressure of rats (before LPS injection) every 3 days. In addition, an automatic biochemical analyzer (Roche) was used to measure the 24-h urine protein of rats (before LPS injection) every 3 days. The presence of elevated arterial pressure exceeding $16 \mathrm{kPa}$ (normal blood pressure value $=14.5 \pm 0.5 \mathrm{kPa}$ ), and a concurrent large increase in urinary protein at $24 \mathrm{~h}$ indicated the successful establishment of the PE model in rats.

\section{Animal treatment}

The LPS-induced PE model rats were assigned into:

(1) the LPS group (untreated); LPS + DMSO group: during PE modeling, DMSO solution (Sigma-Aldrich) was injected intraperitoneally from the 7 th to 18 th day of pregnancy at a dose of $60 \mathrm{mg} / \mathrm{kg} / \mathrm{day}$;

(2) LPS + TMP group: during PE modeling, TMP injection (20 mg/mL, Wuxi No. 7 Pharmaceutical Factory, China) was injected intraperitoneally from the 7 th to 18 th day of pregnancy at a dose of $60 \mathrm{mg} / \mathrm{kg} /$ day (Gu et al. 2019);

(3) LPS + agomir-NC group: during PE modeling, lentiviral vectors containing negative control sequence of miR16-5p agomir were injected into a rat tail vein from the 13th day to 18 th day at a dose of $0.5 \mathrm{mg} / \mathrm{kg} /$ day;

(4) LPS + agomir-16-5p group: during PE modeling, lentiviral vectors overexpressing miR-16-5 $p$ were injected into a rat tail vein from the 13 rd day to 18th day at a dose of $0.5 \mathrm{mg} /$ $\mathrm{kg} / \mathrm{day}$;

(5) agomir-NC+DMSO group: during PE modeling, the rats were injected intraperitoneally with DMSO solution at the dose of $60 \mathrm{mg} / \mathrm{kg} /$ day from the 7 th to the 18th day of pregnancy, and the negative control of miR-16-5p agomir was injected into a tail vein at the dose of $0.5 \mathrm{mg} / \mathrm{kg} /$ day;

(6) agomir-16-5p+DMSO group: during PE modeling, rats were injected intraperitoneally with DMSO solution from the 7th to the 18th day of pregnancy at a dose of $60 \mathrm{mg} /$ $\mathrm{kg} /$ day. From the 13th day to 18 th day, lentiviral vectors overexpressing miR-16-5p was injected into a tail vein at a dose of $0.5 \mathrm{mg} / \mathrm{kg} /$ day;

(7) agomir-16-5p+TMP group: during PE modeling, TMP solution was injected intraperitoneally at a dose of 60 $\mathrm{mg} / \mathrm{kg} /$ day on the 7 th to 18 th days of pregnancy, and the lentiviral vectors overexpressing miR-16-5p was injected at a dose of $0.5 \mathrm{mg} / \mathrm{kg} /$ day through a tail vein from the 13 th day to 18 th day. The agomir-16-5p and agomir-NC were purchased from GenePharma (Shanghai, China). From the 3rd day of pregnancy, the arterial blood pressure and 24-h urine protein of the rats were monitored every 3 days. On the 19th day, all rats were killed by overdose with intraperitoneal injection of sodium pentobarbital. The rats were given a Cesarean section, and the placenta tissue was removed and rinsed with normal saline. One half of the sample was fixed by immersion in $4 \%$ formaldehyde solution, embedded in paraffin and sectioned for $\mathrm{HE}$ staining (Zhou et al. 2017). The other half was stored at $-80^{\circ} \mathrm{C}$ for molecular analysis. 


\section{Human trophoblast cell culture}

Human trophoblast cell line JEG3 was purchased from the Medical Research Center of Beijing Chaoyang Hospital. JEG-3 cells were cultured in DMEM (4.5 g/L Glucose) (Gibco) containing 10\% FBS (HyClone, Logan, UT, USA) and cultured at $37^{\circ} \mathrm{C}$ with $5 \% \mathrm{CO}_{2}$. The culture medium was renewed every 2 days and passaged every 5 days (Li et al. 2019).

\section{TMP treatment of JEG3 cells}

JEG3 cells in logarithmic growth phase were digested with $0.25 \%$ trypsin to make a single cell suspension. The cells were plated at $5 \times 10^{4}$ cells/well in a 24-well plate and cultured overnight. After that, TMP solutions with a final concentration of 0 (the same volume of PBS solution), 2.5, 5 and $10 \mathrm{nM}$ were added to the medium. Then the cells were first cultured in a closed container at $37^{\circ} \mathrm{C}, 5 \% \mathrm{CO}_{2}, 94.5 \% \mathrm{~N}_{2}$, and $0.5 \%$ $\mathrm{O}_{2}$ for 8 hours, and then transferred to a constant temperature incubator at $37^{\circ} \mathrm{C}, 5 \% \mathrm{CO}_{2}$, and $20 \% \mathrm{O}_{2}$ for $16 \mathrm{~h}$.

\section{Cell transfection and grouping}

The mimic-NC, miR-16-5p mimic (Catalog No. miR100000691-5), inhibitor-NC and miR-16-5p inhibitor (Catalog No. miR20000069-1-5) were purchased from Guangzhou RiboBio Co., Ltd. (Guangzhou, China), and transduced using Lipofectamine 2000 (Invitrogen) at a concentration of 100 $\mathrm{nm} / 1000$ cells. ENLs reagent (enhanced infection solution; Catalog No. REVG0002, GeneChem Co. Ltd., Shanghai, China) was applied according to the manufacturers' protocols to transfect recombinant lentiviruses containing IGF-2-1 shRNA, IGF-2-2 shRNA, and sh-NC empty vector (all lentiviral vectors were purchased from GeneChem Co. Ltd., Shanghai, China). The transfected JEG3 cells were all cultured at $37^{\circ} \mathrm{C}$ and $5 \% \mathrm{CO}_{2}$ for $48 \mathrm{~h}$ for subsequent experiments.

Untransfected JEG3 cells or those transfected for $48 \mathrm{~h}$ were plated at $5 \times 10^{4}$ cells/well in 24-well plates and cultured overnight. JEG3 cells are grouped as follows: (1) control group (untransfected cells as a control); (2) mimic-NC group (cells transfected with miR-16-5p negative control plasmid); (3) miR-16-5p mimic group (cells transfected with miR-16-5p mimic plasmid); (4) inhibitor-NC group (cells transfected with miR-16-5p negative control plasmid); (5) miR-16-5p inhibitor group (cells transfected with miR-16-5p inhibitor plasmid); (6) sh-NC group (cell transfected with sh-NC empty vector); (7) sh-IGF-2 group (cell transfected with IGF-2 shRNA recombinant lentivirus); (8) sh-IGF-2-1 group (cells transfected with recombinant lentivirus expressing IGF-2-1 shRNA); (9) sh-IGF-2-2 group (Cells transfected with recombinant lentivirus expressing IGF-2-2 shRNA); (10) inhibitor-NC+sh-NC group (cells transfected with inhibitor-NC plasmid + sh-NC empty vector); (11) inhibitor-NC+sh-IGF-2 group (cells transfected with inhibitor-NC plasmid+sh-IGF-2 recombinant lentivirus); (12) miR-16-5p inhibitor + sh-IGF-2 group (cells transfected with miR-16-5p inhibitor plasmid+sh-IGF-2 recombinant lentivirus); (13) miR-16-5p mimic + DMSO group (cells were transfected with miR-16-5p mimic plasmid and $10 \mathrm{nM}$ vehicle control DMSO was added); (14) miR-16-5p mimic +TMP group (cell were transfected with miR-16-5p mimic plasmid and added with $10 \mathrm{nM}$ TMP); (15) sh-IGF-2 + DMSO group (cells were transfected with sh-IGF-2 recombinant lentivirus and added with $10 \mathrm{nM}$ DMSO); (16) sh-IGF-2 + TMP group (cells transfected with sh-IGF-2 recombinant lentivirus and treated with $10 \mathrm{nMTMP}$ ).

\section{EdU assay}

The cells to be tested were seeded in a 24-well plate, and three replicates were made for each group. Cells were incubated with $\mathrm{EdU}$ (concentration $=10 \mu \mathrm{mol} / \mathrm{L}$ ) for $2 \mathrm{~h}$. The medium was aspirated, and the cells were fixed at room temperature in a PBS solution containing 4\% paraformaldehyde. DAPI was employed to stain the nucleus. After mounting, randomly selected 6-10 fields were observed under a fluorescence microscope, and the number of EdU positive cells in each field was recorded.

\section{Transmission electron microscope (TEM) observation}

The placental tissue was cut into pieces, and these tissue pieces or JEG3 cells were fixed with a fixing solution $(2 \%$ paraformaldehyde, $2.5 \%$ glutaraldehyde) at $4{ }^{\circ} \mathrm{C}$ for $1 \mathrm{~h}$, and then in 1\% osmic acid for 1.5 hours. Tissues were dehydrated with gradient alcohol, dipped into epoxy resin overnight, embedded, and polymerized for $24 \mathrm{~h}$ at 35, 45, and then $60^{\circ} \mathrm{C}$. After ultra-thin sectioning and lead-uranium staining, slices were observed using a transmission electron microscope (JEM-1011; JEOL, Tokyo, Japan) under an acceleration voltage of $80 \mathrm{kV}$. Photographs were taken using a side-mounted Camera-Megaview III (Soft Imaging System, Münster, Germany).

\section{Western blots}

Tissues or cells were added with pre-cold lysate (R0010, solarbio) containing PMSF and phosphatase inhibitors, ground thoroughly, and lysed on ice. After that, the lysed samples were centrifuged at $6037 \mathrm{~g}$ and $4^{\circ} \mathrm{C}$ for $10 \mathrm{~min}$ to harvest the supernatant. The total protein concentration was measured using a BCA kit (Pierce). Then, $20 \mu \mathrm{g}$ of protein was dissolved in $2 \times$ SDS loading buffer and electrophoresed on 10\% SDSPAGE. The protein was transferred to a PVDF membrane by a wet transfer method, and the membrane was blocked with $5 \%$ skim milk powder at room temperature for $1 \mathrm{~h}$. Membranes were immunoblotted at $4{ }^{\circ} \mathrm{C}$ overnight with diluted primary antibodies rabbit anti-IGF-2 (ab63984, 1:500, Abcam), LC3-II (ab48394, 1 Hg/mL, Abcam), LC3-I (ab128025, $2 \mu \mathrm{g} /$ $\mathrm{mL}$, Abcam), Beclin1 (ab62557, $1 \mu \mathrm{g} / \mathrm{mL}$, Abcam), SQSTM1 (ab91526, $1 \mu \mathrm{g} / \mathrm{mL}$, Abcam), Ki67 (ab92472, 1:5000, Abcam) and GAPDH (ab8245, 1: 10,000). After washing three times with TBST, the membrane was incubated with HRP-labeled secondary antibody $\operatorname{lgG}(1: 1000)$ for $1 \mathrm{~h}$. Immunoreactive bands were visualized using ECL detection kit (BB-3501, Amersham Biosciences). Data were analyzed with the Molecular Imager (Gel DocTM XR, 170-8170) and the associated software Quantity One-4.6.5 (Bio-Rad Laboratories). 
Table 1 Primer sequences for RT-qPCR.

\begin{tabular}{lll}
\hline Gene & Forward $\left(5^{\prime}-3^{\prime}\right)$ & Reverse $\left(5^{\prime}-3^{\prime}\right)$ \\
\hline miR-16-5p & TGGGGTAGCAGCACGTAAA & CTCAACTGGTGTCGTGGAGTC \\
IG & CTCGCTTCGGCAGCACAT & AACGCTTCACGAATTTGCGT \\
IGF-2 & GTGACCAGCAAGGCACAAATC & CACCAAGTAGGCACCACTAAG \\
GAPDH & TCATGAAGTGTGACGTTGACATCCGT & CCTAGAAGCATTTGCGGTGCACGATG \\
\hline
\end{tabular}

\section{RNA isolation and quantitation}

Total RNA was purified from cells using the RNeasy Plus Mini Kit (Qiagen) according to the manufacturer's instructions. IGF-2 was reverse transcribed using PrimeScript RT reagent Kit (Promega). After this, gene expression was quantified using SYBR Green Master Mix (Life Technologies). For the detection of miR-16-5p, cDNA was obtained by RT using the Mir-XTM miRNA First Strand Synthesis Kit (Takara). Quantification of miR-16-5p level was checked by Mir-XTM miRNA qRT-PCR TB GreenTM Kit (Takara). The miR-16-5p (normalized to U6) or IGF-2 gene (normalized to GAPDH and $\beta$-actin) levels were determined using $2^{-\Delta \Delta \mathrm{Ct}}$ method (Table 1) with the formula as $\Delta \Delta \mathrm{CT}=(\mathrm{CT}$ target $-\mathrm{CT}$ internal control) Subject - (CT target - CT internal control) Control. $\mathrm{CT}_{\text {internal control }}$ is the geometric mean of $\beta$-actin and GAPDH CTs. Outliers were excluded if the normalized (delta Ct) values were N2 standard deviations from the group mean. Relative expression levels are reported as fold change and $\Delta \mathrm{Ct}$ values are used for further statistical analysis (Applied Biosystems User Bulletin No. 2).

\section{CCK-8 assay}

JEG3 cell viability as measured using a Cell Counting Kit-8 (CCK-8, Dojindo Molecular Technologies, USA). After $48 \mathrm{~h}$ transfection, cells $\left(5 \times 10^{3}\right.$ cells per well) were seeded in a 96-well plate, and incubated in a $37^{\circ} \mathrm{C}, 5 \% \mathrm{CO}_{2}$ incubator. Each group was repeated three times. The 96-well plates were removed at 24,48 , and $72 \mathrm{~h}$. After adding $10 \mu \mathrm{L} /$ well CCK-8 solution under sterile conditions, the incubation was continued in a $37^{\circ} \mathrm{C}, 5 \% \mathrm{CO}_{2}$ incubator for about $1.5 \mathrm{~h}$. The OD value was measured with an automatic microplate reader (Molecular Devices, USA) at a wavelength of $450 \mathrm{~nm}$.

\section{Transwell migration assay}

Cells in logarithmic growth phase were digested with $0.25 \%$ trypsin, resuspended in serum-free DMEM and adjusted to a cell density of $5 \times 10^{4}$ cells $/ \mathrm{mL}$. Cell suspension $(100 \mu \mathrm{L})$ was added to the upper chamber of a 24-well Transwell chamber (BioCoat; BD Biosciences, San Jose, CA, USA). Then, $500 \mu \mathrm{L}$ of $10 \%$ FBS-containing DMEM was added in advance to the lower chamber, and incubated in a $37^{\circ} \mathrm{C}, 5 \% \mathrm{CO}_{2}$ incubator for $24 \mathrm{~h}$. The chamber was fixed with methanol for $10 \mathrm{~min}$ and stained for 10 min using crystal violet. A cotton swab was employed to carefully wipe the cells from the upper surface of chamber. The chamber polycarbonate membrane was sealed in a glass slide with a neutral resin, and cells were counted in six random fields under a microscope.

\section{Luciferase activity assay}

The luciferase reporter gene assay was adopted to verify the targeting relationship between IGF-2 and miR-16-5p. IGF-2 3'UTR gene fragment was artificially synthesized, and the complementary sequence mutation site of the seed sequence was designed on the IGF-2 wild type, and introduced into the pMIR-reporter (Promega) via the endonuclease sites Spel and Hind III) to construct the target gene IGF-2 dual-luciferase reporter gene vector and mutants with mutations in the binding site to miR-16-5p: PGLO-IGF-2 Wt and PGLO-IGF-2 Mut. Wild type (WT) and mutant (MUT) luciferase reporter plasmids were co-transfected with miR-16-5p mimic plasmid/mimic-NC plasmid and Renilla vector (pRL-TK; Promega), respectively, into HEK-293T cells. Twenty-four hours after transfection, the cells were lysed according to the Dual-Luciferase Reporter Assay Kit (Promega), incubated at $25^{\circ} \mathrm{C}$ for $20 \mathrm{~min}$, and the supernatant was collected. The Dual-Luciferase Reporter Assay Kit was employed to measure firefly luciferase activity and Renilla luciferase activity. The relative luciferase activity was calculated as the ratio of fire fly luciferase to Renilla luciferase.

\section{Statistical analysis}

All data were processed using SPSS 21.0 statistical software (IBM Corp). Measurement data were expressed as mean \pm S.D. Conforming to normal distribution and homogeneous variance, data between two groups were compared using unpaired $t$ test. The comparison between multiple groups was analyzed by one-way ANOVA with Tukey's post hoc test. Data comparison between groups at different time points was performed by two-way ANOVA. Pearson correlation analysis was carried out for the correlation between miR-16-5p and IGF-2. $P<0.05$ indicates that the difference is statistically significant.

\section{Results}

\section{TMP has a good therapeutic effect on PE rat models}

We employed tail vein injection of LPS to develop a PE model in rats, and monitored the arterial pressure and $24 \mathrm{~h}$ urine protein content of the rats from the $3 \mathrm{rd}$ to the 18 th day of their pregnancy. There was no significant change in arterial pressure and $24 \mathrm{~h}$ urine protein in rats of the blank group from the 3 rd to the 18th day $(P>0.05)$. Relative to the blank group, the arterial pressure of LPS-induced rats increased with the passage of time $(>30 \mathrm{mmHg})$ from the 6th day, and the $24 \mathrm{~h}$ urine protein content also rose $(P<0.05)$ (Fig. $1 \mathrm{~A}$ and $B$ ). These results indicated that the PE rat model was successfully established. 

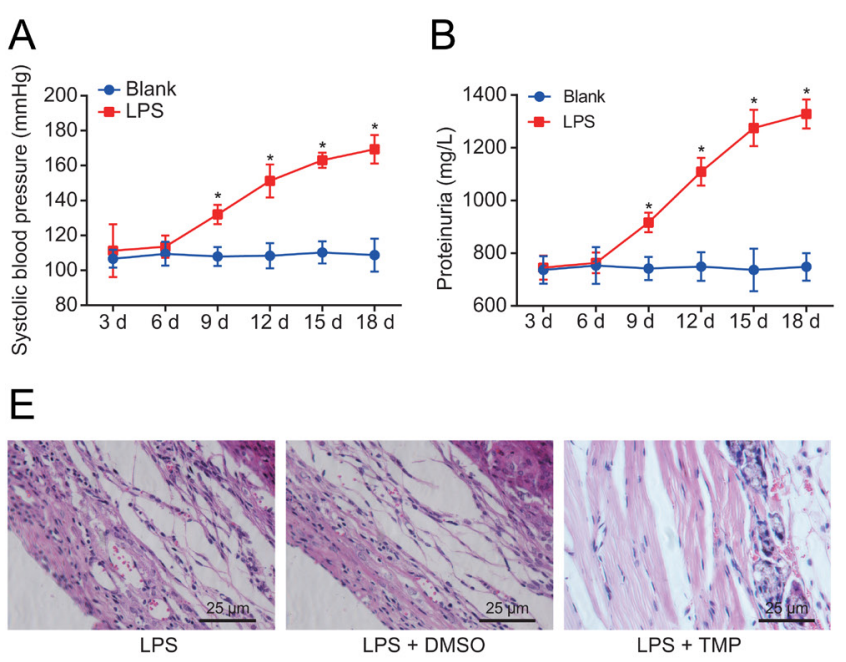
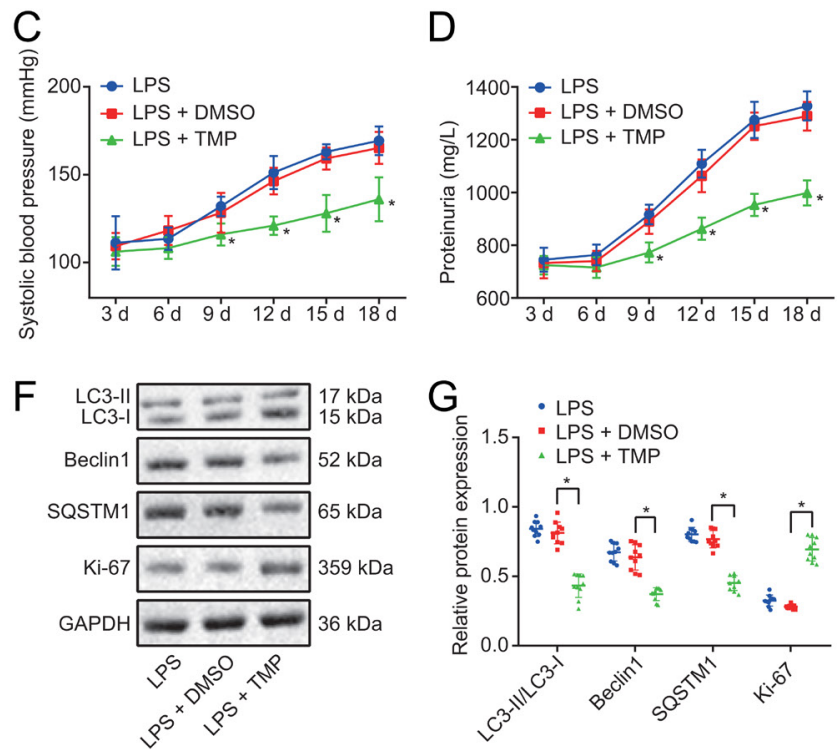

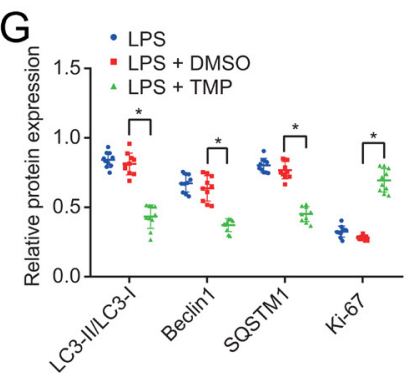

Figure 1 Therapeutic effect of TMP on LPS-induced PE rat model. (A) Changes in arterial pressure of rats with/without LPS induction at various time points monitored by a blood pressure monitor; (B) changes of $24 \mathrm{~h}$ urine protein content of rats with/without LPS induction at various time points monitored by an automatic biochemical instrument; $(\mathrm{C})$ the impact of TMP treatment on arterial pressure of LPS-induced rats monitored by a blood pressure monitor; (D) the impact of TMP treatment on 24-hour urine protein content in LPS-induced rats monitored by an automatic biochemical instrument; (E) HE staining to observe the pathological characteristics of placental tissue ( $\times 400)$; (F and G) Western blot assay to measure autophagy-related proteins LC3-II/LC3-I, Beclin1, and SQSTM1 and proliferation-related proteins Ki67 expression in placental tissues. ${ }^{*} P<0.05$ vs blank group or LPS + DMSO group, $n=10$. Measurement data are expressed as mean \pm S.D. Comparisons between groups were performed using one-way ANOVA with Tukey's post hoc test. Data comparison between groups at different time points was performed by two-way ANOVA.

To unveil the effect of TMP on the development of PE in rats, we injected TMP into PE rats and used DMSO as a vehicle control. DMSO vehicle had no significant effect on the arterial pressure and $24 \mathrm{~h}$ urine protein content of LPS-induced rats at any time point $(P>0.05)$. However, TMP treatment reduced the arterial pressure and $24 \mathrm{~h}$ urine protein content of LPS-induced rats at various time points $(P<0.05)$ (Fig. 1C and D). TEM observation showed that DMSO did not change the number of autophagosomes in the trophoblast cells of LPS-induced rats. However, TMP treatment reduced the number of autophagosomes in trophoblast cells of placental tissue in LPS-induced rats $(P<0.05)$ (Supplementary Fig. $1 \mathrm{~A}$, see section on supplementary materials given at the end of this article). The HE staining results displayed obvious placental tissue cysts, basal trophoblast giant cell proliferation, elevated vacuole cells, thickened basal bands, and obvious inflammatory cell infiltration in the LPS-induced rats with or without DMSO. After TMP treatment, the incidence of cysticity, basement thickening, and inflammatory cell infiltration were lower in placental tissues of LPS-induced rats (Fig. 1E). Western blot assay showed that DMSO could not affect the expression of autophagy-related proteins LC3-II/ LC3-I, Beclin1, and SQSTM1, and the expression of proliferation-related protein Ki67 $(P>0.05)$. However, TMP treatment reduced the protein expression of
LC3-II/LC3-I, Beclin1, and SQSTM1, and elevated the protein expression of Ki67 $(P<0.05)$ (Fig. $1 \mathrm{~F}$ and $\mathrm{G}$ ). The above results suggest that TMP has an alleviatory effect on PE rat models.

\section{TMP inhibits autophagy and enhances viability and migration in JEG3 cell}

We added TMP at different concentrations $(0,2.5$, 5 , and $10 \mathrm{nM})$ to the medium to probe the effect of TMP on the progress of PE in JEG3 cells. TEM results demonstrated that relative to $0 \mathrm{nM}$ TMP, TMP at 2.5, 5 , and $10 \mathrm{nM}$ reduced the number of autophagosomes formed in JEG3 cells, and higher concentrations led to the formation of fewer autophagosomes, thus showing certain concentration dependence (Supplementary Fig. 1B). CCK-8 assay (Fig. 2A) and Transwell assay (Fig. 2B and $\mathrm{C}$ ) showed that JEG3 cell viability and migration ability were elevated with increasing TMP concentration, showing certain concentration dependence $(P<0.05)$. Western blot assay showed that versus $0 \mathrm{nM}$ TMP, TMP at 2.5, 5, and $10 \mathrm{nM}$ diminished the protein expression of LC3-II/LC3-I, Beclin1, and SQSTM1 in JEG3 cells, and elevated the protein expression of Ki67, indicating a certain concentration dependence $(P<0.05)$ (Fig. 2D). The above results show that TMP can repress autophagy of JEG3 cells and promote viability and migration concentration-responsively. 

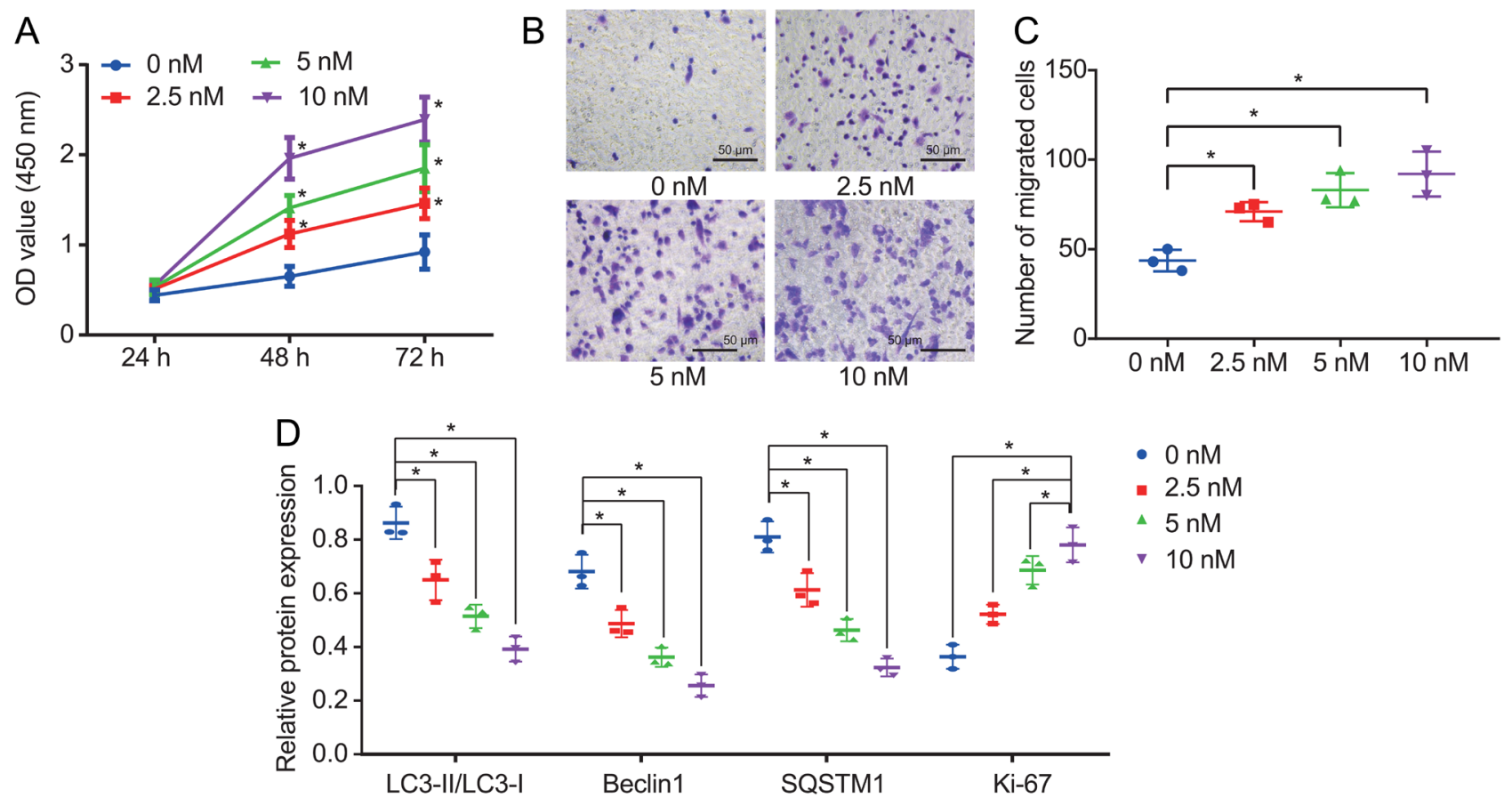

Figure 2 TMP inhibits autophagy and enhances viability and migration in JEG3 cells. (A) CCK-8 assay to detect the effect of TMP at different concentrations on JEG3 cell proliferation; (B and C) Transwell assay to detect the effect of TMP at different concentrations on JEG3 cell migration (× 200); (D) Western blot assay to detect the effect of TMP at different concentrations on the protein expression of LC3-II/LC3-I, Beclin1,

SQSTM1 and Ki67 in JEG3 cells. ${ }^{*} P<0.05$ vs TMP at $0 \mathrm{nM}$. Measurement data are expressed as mean \pm S.D. Comparisons between groups were performed using one-way ANOVA with Tukey's post hoc test. Data comparison between groups at different time points was performed by two-way ANOVA. Cellular experiment was repeated three times.

\section{MiR-16-5p enhances autophagy and inhibits viability and migration of JEG3 cells}

LPS-induced rats with/without DMSO treatment showed upregulated miR-16-5p in rat placental tissue $(P<0.05)$, but TMP treatment reduced miR-16-5p expression in rat placental tissue $(P<0.05)$ (Fig. 3A). In TMP-treated JEG3 cells, versus TMP at $0 \mathrm{nM}, \mathrm{TMP}$ at $2.5,5$ and 10 nM reduced miR-16-5p expression $(P<0.05)$ (Fig. $3 \mathrm{~B})$. These results indicate that miR-16-5p was highly expressed in PE rats, and TMP can reduce the expression of miR-16-5p in PE rats. To investigate whether miR16-5p participated in the development of PE, we overexpressed or inhibited miR-16-5p expression in JEG3 cells, respectively. qRT-PCR results showed that relative to mimic-NC, miR-16-5p expression was elevated in the presence of miR-16-5p mimic $(P<0.05)$, while relative to inhibitor- $\mathrm{NC}$, the expression of miR$16-5 p$ was downregulated in the presence of miR-16-5p inhibitor $(P<0.05)$ (Fig. 3C), indicating that miR-16-5p expression was successfully up or downregulated in JEG3 cells.

TEM observations showed that miR-16-5p mimic elevated the number of autophagosome formation, while miR-16-5p inhibitor reduced the number of autophagosome formation (Supplementary Fig. 1C). CCK-8 assay (Fig. 3D) and Transwell assay (Fig. 3E and F) showed that miR-16-5p mimic inhibited cell viability and migration capacity, while miR-16-5p inhibitor enhanced cell viability and migration capacity $(P<0.05)$. Western blot assay revealed that miR-16-5p mimic elevated the protein expression of LC3-II/LC3-I, Beclin1 and SQSTM1, and reduced the protein expression of Ki67, but that miR-16-5p inhibitor reversed these changes $(P<0.05)$ (Fig. 3G). The above results indicate that miR-16-5p strengthened autophagy of JEG3 cells and repressed their viability and migration.

\section{IGF-2 is a target gene of miR-16-5p}

The miRNA target gene prediction website miRDB (http://www.mirdb.org/) showed that miR-16-5p could target the IGF-2 gene (Fig. 4A). The luciferase reporter gene assay results verified the binding relationship, showing that versus mimic-NC, the luciferase activity of miR-16-5p mimic and IGF-2 3'UTR-wt fusion was reduced $(P<0.05)$, but the luciferase activity of its fusion with IGF-2 3'UTR-mut was hardly affected $(P>0.05)$ (Fig. 4B). In addition, miR-16-5p mimic diminished the expression of IGF-2 $(P<0.05)$, and miR-16-5p inhibitor elevated the expression of IGF-2 $(P<0.05)$ (Fig. 4C, D and E). qRT-PCR and Western blot identified that the expression of IGF-2 diminished in placental tissue of LPSinduced rats $(P<0.05)$, and that TMP enhanced IGF-2 

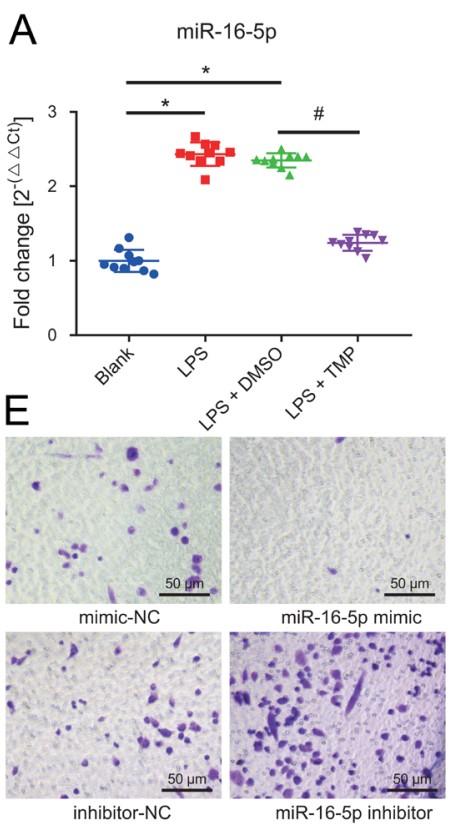

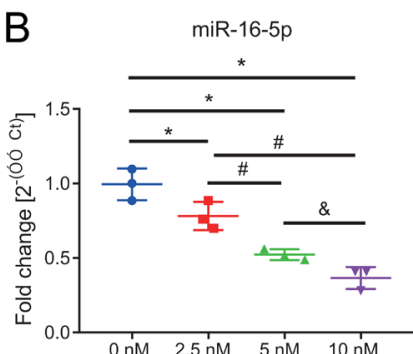

$\mathrm{F}$

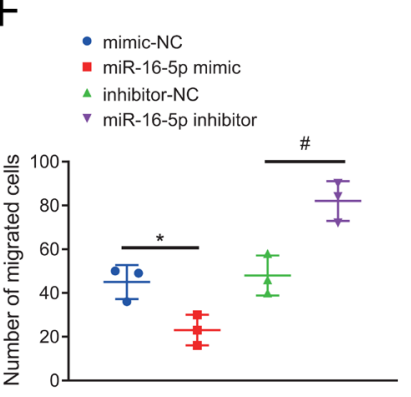

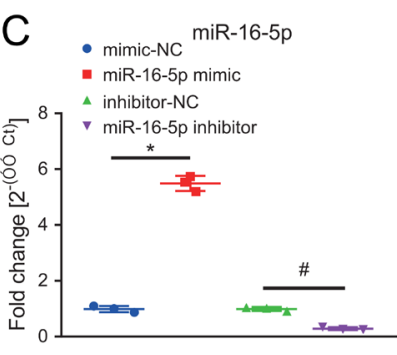

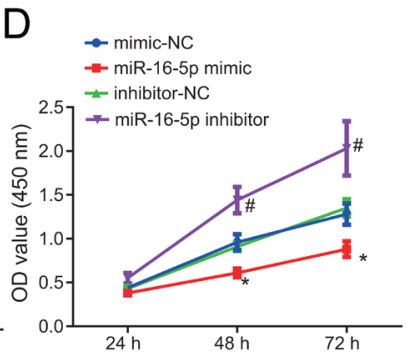

G

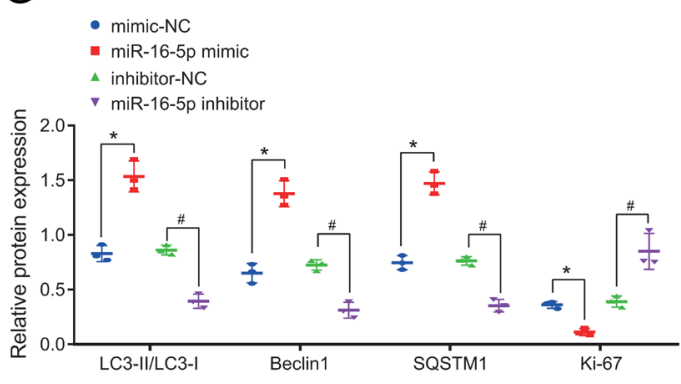

Figure 3 MiR-16-5p promotes autophagy and inhibits viability and migration of JEG3 cells. (A) qRT-PCR to detect miR-16-5p expression in PE rat placental tissue; (B) qRT-PCR to detect miR-16-5p expression in TMP-treated JEG3 cells; (C) qRT-PCR to detect miR-16-5p expression in JEG3 cells in the presence of miR-16-5p mimic or inhibitor; (D) CCK-8 assay to detect the effects of miR-16-5p on JEG3 cell viability; (E and F) Transwell assay to detect the effects of miR-16-5p on JEG3 cell migration capacity $(\times 200)$; (G) Western blot assay to detect the effects of miR-16-5p on protein expression of LC3-II/LC3-I, Beclin1, SQSTM1 and Ki67 in JEG3 cells; ${ }^{*} P<0.05$ vs. blank group, TMP at 0 nM or mimic-NC group; $\# P<0.05$ vs LPS + DMSO group, TMP at $2.5 \mathrm{nM}$ or inhibitor-NC group; $\& P<0.05$ vs TMP at $5 \mathrm{nM}$. Measurement data are expressed as mean \pm S.D. Comparisons between groups were performed using one-way ANOVA with Tukey's post hoc test. Data comparison between groups at different time points was performed by two-way ANOVA, $n=10$ in panel A. Cellular experiments were repeated three times.
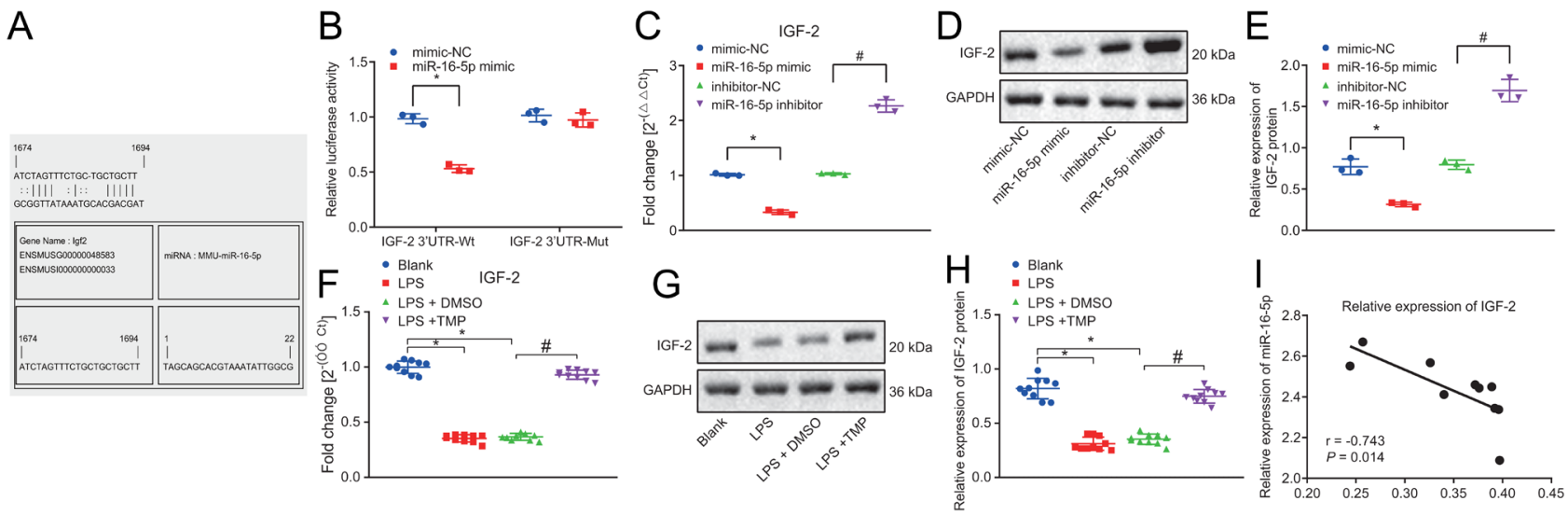

Figure 4 IGF-2 is a target gene of miR-16-5p. (A) microRA.org (http://www.microrna.org/) to predict and analyze the binding site of miR-16-5p and IGF-2; (B) dual luciferase assay to verify the binding of miR-16-5p and IGF-2; (C) qRT-PCR to detect IGF-2 mRNA expression in JEG3 cells after transfection; ( $D$ and E) Western blot assay to detect IGF-2 protein expression in JEG3 cells after transfection; (F) qRT-PCR to detect IGF-2 mRNA expression in placental tissue; $(\mathrm{G}$ and $\mathrm{H}$ ) Western blot assay to detect IGF-2 protein expression in placental tissue; (I) Pearson correlation analysis to evaluate correlation of miR-16-5p level and IGF-2 mRNA in placental tissue; ${ }^{*} P<0.05$ vs mimic-NC group or blank group; \#P< 0.05 vs inhibitor-NC group or LPS + DMSO group. Measurement data are expressed as mean \pm S.D. The differences between groups were analyzed using unpaired $t$ test. Comparisons between groups were performed using one-way ANOVA with Tukey's post hoc test. Data comparison between groups at different time points was performed by two-way ANOVA with Bonferroni post hoc test, $n=10$ in panel F, G, H. Cellular experiments were repeated three times. 
expression in LPS-induced rats $(P<0.05)$ (Fig. 4F, G and $\mathrm{H})$. Pearson correlation analysis showed that the level of miR-16-5p in JEG3 cells was negatively correlated with the expression of IGF-2 mRNA ( $r=-0.743, P<0.05)$ (Fig. $4 \mathrm{I}$ ). The above results indicate that IGF-2 is a target gene of miR-16-5p.

\section{MiR-16-5p enhances autophagy and represses viability and migration of JEG3 cells by targeting IGF-2}

After knocking down IGF-2 expression in JEG3 cells, qRT-PCR results showed that, relative to sh-NC, IGF-2 expression was diminished by sh-IGF-2, sh-IGF-2-1, and sh-IGF-2-2 treatments, with the most pronounced effect caused by sh-IGF-2 (Fig. 5A). We then downregulated the expression of miR-16-5p and IGF-2 in JEG3 cells. Relative to inhibitor-NC + sh-NC, inhibitor-NC + sh-IGF-2 only downregulated the expression of IGF-2, while miR-16-5p inhibitor + sh-NC repressed miR-16-5p and upregulated IGF-2; meanwhile, miR-16-5p inhibitor + sh-IGF-2 downregulated both miR-16-5p and IGF-2 expression $(P<0.05)$ (Fig. 5B). Thus, the intended downregulation of miR-16-5p and IGF-2 expression in JEG3 cells was successful.
A

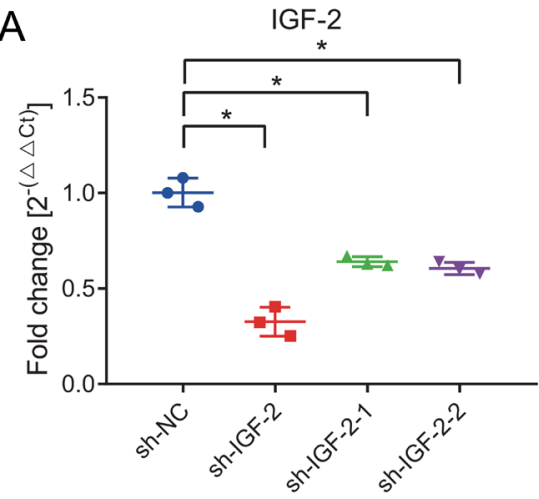

$\mathrm{D}$

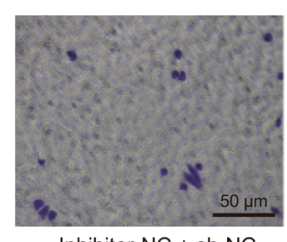

Inhibitor-NC + sh-NC
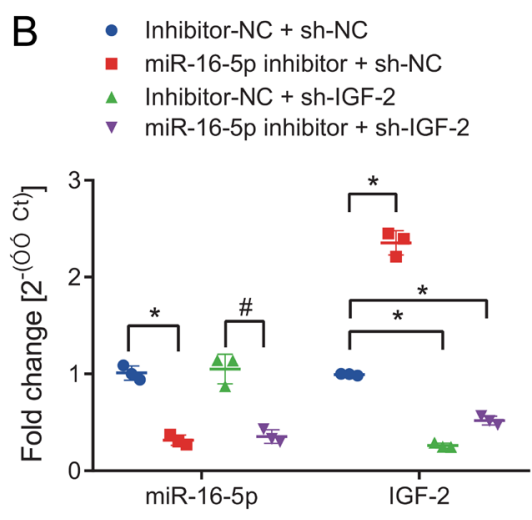

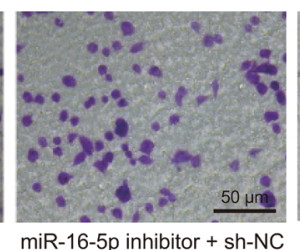

miR-16-5p inhibitor + sh-NC
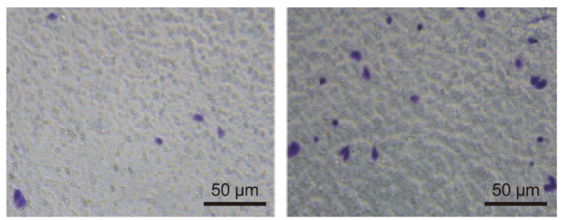

Inhibitor-NC + sh-IGF-2 miR-16-5p inhibitor + sh-IGF-2

$$
\begin{array}{cll}
- & & \text { Inhibitor-NC + sh-NC } \\
& \quad & \text { miR-16-5p inhibitor + sh-NC } \\
& \Delta & \text { Inhibitor-NC + sh-IGF-2 } \\
& \nabla & \text { miR-16-5p inhibitor + sh-IGF-2 }
\end{array}
$$

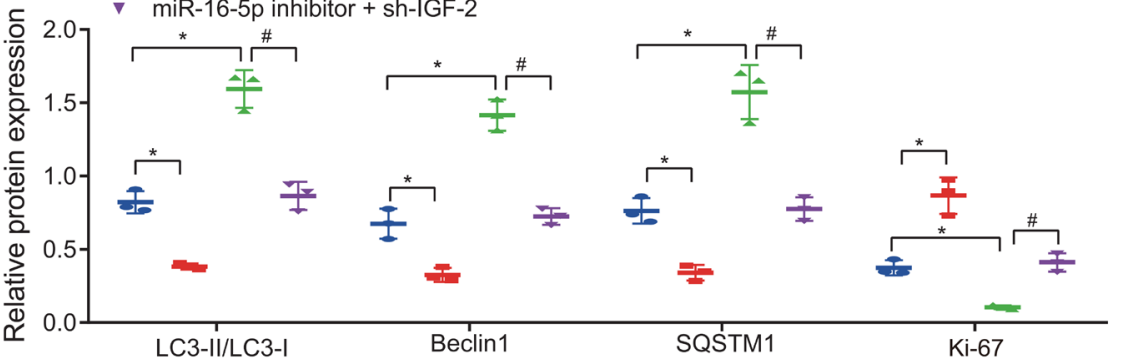

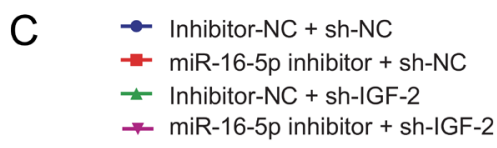

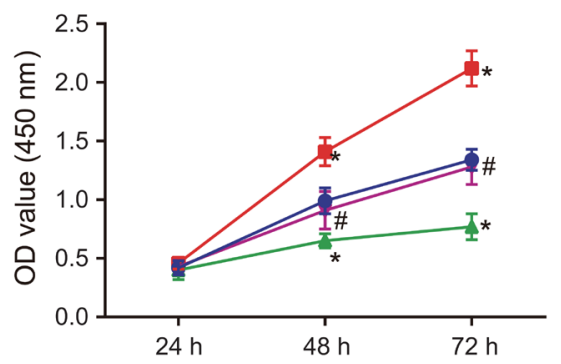

- Inhibitor-NC + sh-NC

E miR-16-5p inhibitor + sh-NC

$\Delta \quad$ Inhibitor-NC + sh-IGF-2

$\checkmark$ miR-16-5p inhibitor + sh-IGF-2

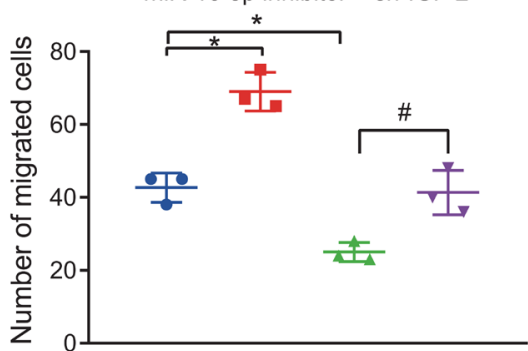

Figure 5 MiR-16-5p enhances autophagy and represses viability and migration of JEG3 cells by targeting IGF-2. (A) qRT-PCR to detect the efficiency of shRNA targeting IGF-2 in JEG3 cells; (B) qRT-PCR to detect the expression of miR-16-5p and IGF-2 in the presence of miR-16-5p inhibitor and sh-IGF-2 in JEG3 cells; (C) CCK-8 assay to detect the viability of JEG3 cells in the presence of miR-16-5p inhibitor and sh-IGF-2; ( $D$ and E) Transwell assay to detect the migration capacity of JEG3 cells in the presence of miR-16-5p inhibitor and sh-IGF-2 ( $\times 200)$; (F) Western blot assay to detect protein expression of LC3-II/LC3-I, Beclin1, SQSTM1 and Ki67 in JEG3 cells in the presence of miR-16-5p inhibitor and sh-IGF-2; ${ }^{*} P<0.05$ vs sh-NC group or inhibitor-NC + sh-NC group; $\# P<0.05$ vs inhibitor-NC + sh-IGF-2 group. Measurement data are expressed as mean \pm S.D. Comparisons between groups were performed using one-way ANOVA with Tukey's post hoc test. Data comparison between groups at different time points was performed by two-way ANOVA. Cellular experiments were repeated three times. 
TEM observation (Supplementary Fig. 1D) showed that relative to inhibitor-NC+sh-NC, treatment with miR-16-5p inhibitor + sh-NC diminished the number of autophagosomes formed in cells, while inhibitor-NC+sh-IGF-2 elevated autophagosome formation. In comparison with inhibitor-NC+ sh-IGF-2, treatment with miR-16-5p inhibitor + sh-IGF-2 suppressed the autophagosome formation in cells $(P<0.05)$. The CCK-8 assay (Fig. $5 \mathrm{C})$ and Transwell assay (Fig. 5D and E) showed that miR-16-5p inhibitor + sh-NC enhanced cell viability and migration compared to inhibitor-NC+sh-NC, while inhibitor-NC+sh-IGF-2 reduced cell viability and migration ability $(P<0.05)$. In comparison with inhibitor-NC+sh-IGF-2, treatment with miR-16-5p inhibitor + sh-IGF-2 augmented cell viability and migration ability $(P<0.05)$. Western blot assay results showed that miR-16-5p inhibitor + sh-NC reduced the expression of LC3-II/LC3I, Beclin1 and SQSTM1, and elevated the expression of Ki67, as compared to inhibitor-NC+sh-NC, and that inhibitor-NC+sh-IGF-2 treatment elevated the protein expression of LC3-II/LC3-I, Beclin1, and SQSTM1, and diminished the protein expression of Ki67 $(P<0.05)$. In comparison with inhibitor-NC+sh-IGF-2, treatment with miR-16-5p inhibitor + sh-IGF-2 reduced protein expression of LC3-II/LC3-I, Beclin1, and SQSTM1, and elevated protein expression of Ki67 $(P<0.05)$ (Fig. 5F). The above results suggest that miR-16-5p augments autophagy of JEG3 cells and curbs their viability and migration by targeting IGF-2.

\section{TMP inhibits autophagy and enhances viability and migration of JEG3 cells by regulating the miR-16-5p/ IGF-2 axis}

Next, we attempted to investigate whether TMP affected the PE process by regulating the miR-16-5p/IGF-2 axis. We added TMP to JEG3 cells transfected with miR-16-5p mimic or sh-IGF-2, respectively. TEM observations showed that TMP reduced the autophagosome formation in miR-16-5p mimic-treated and sh-IGF-2-treated JEG3 cells (Supplementary Fig. 1E). CCK-8 assay (Fig. 6A) and Transwell assay (Fig. 6B and C) showed that TMP enhanced the viability and migration capacity of miR16-5p mimic-treated and sh-IGF-2-treated JEG3 cells. Western blot assay results showed that TMP diminished the expression of LC3-II/LC3-I, Beclin1 and SQSTM1, and elevated the expression of Ki67 protein in miR16-5p mimic-treated and sh-IGF-2-treated JEG3 cells $(P<0.05)$ (Fig. 6D). The above results indicate that TMP inhibits autophagy and augments viability and migration of JEG3 cells by regulating the miR-16-5p/IGF-2 axis.
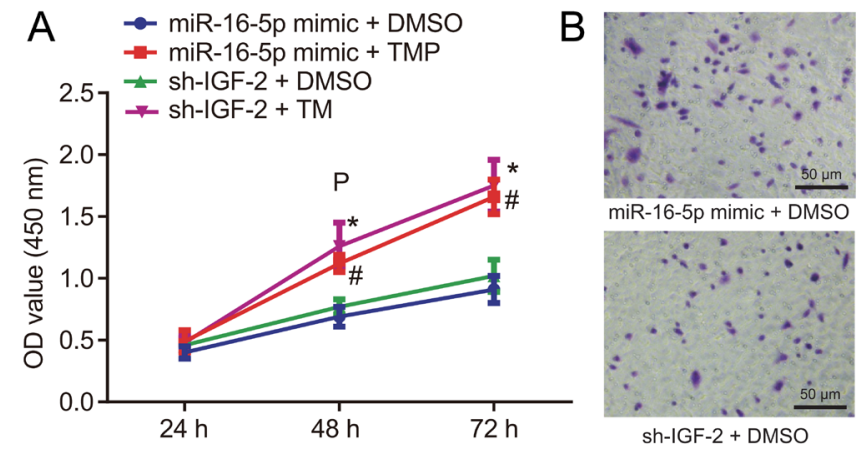

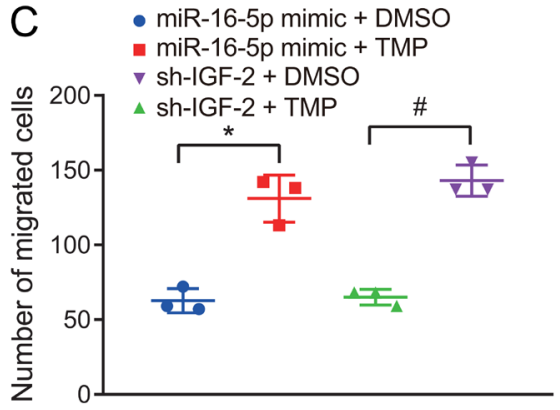

sh-IGF-2 + TMP
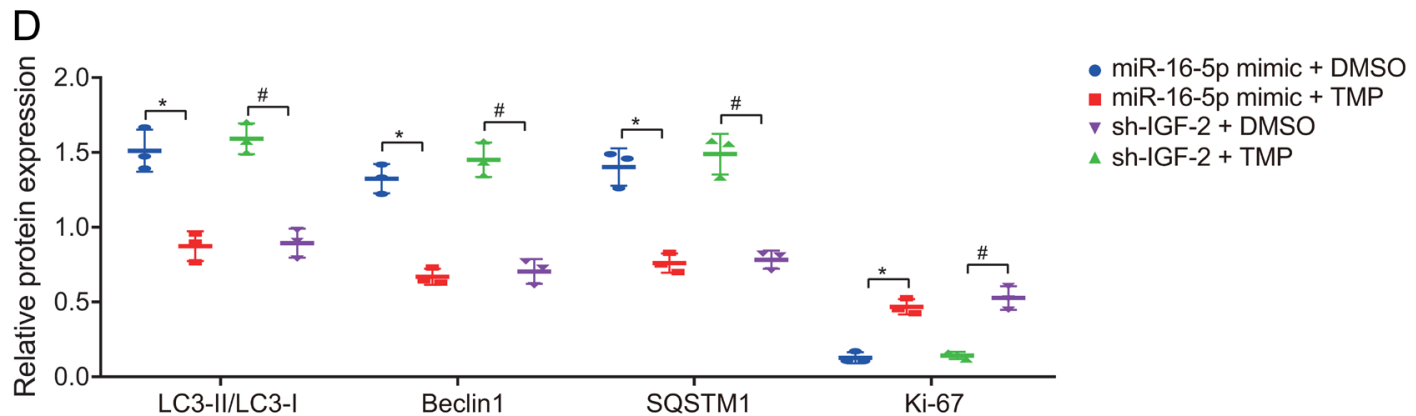

Figure 6 TMP inhibits autophagy and enhances viability and migration of JEG3 cells by regulating the miR-16-5p/IGF-2 axis. (A) CCK-8 assay to detect the viability of JEG3 cells in the presence of miR-16-5p, sh-IGF-2 and TMP; (B and C) Transwell assay to detect the migration ability of JEG3 cells in the presence of miR-16-5p, sh-IGF-2 and TMP $(\times 200)$; (D) Western blot assay to detect the protein expression of LC3-II/LC3-I, Beclin1, SQSTM1 and Ki67 in JEG3 cells in the presence of miR-16-5p, sh-IGF-2 and TMP; ${ }^{*} P<0.05$ vs miR-16-5p mimic + DMSO group; \#P< 0.05 vs sh-IGF-2 + DMSO group. Measurement data are expressed as mean \pm S.D. Comparisons between groups were performed using one-way ANOVA with Tukey's post hoc test. Data comparison between groups at different time points was performed by two-way ANOVA. Cellular experiments were repeated three times. 


\section{TMP hinders the progression of PE in rats by regulating the miR-16-5p/IGF-2 axis}

We further injected lentiviral vectors containing agomir16-5p or sh-IGF-2 into PE model rats to verify whether TMP affects PE progression in rats by regulating the miR-16-5p/IGF-2 axis. On the 19th day of pregnancy, rats were subjected to cesarean section, and placental tissues were removed. The expression of miR-16-5p in placental tissues of rats was detected by RT-qPCR. RT-qPCR results showed that agomir-16-5p elevated miR-16-5p expression and reduced IGF-2 mRNA expression in rat placental tissue $(P<0.05)$. Meanwhile, sh-IGF-2 did not change the expression of miR-16-5p but reduced the expression of IGF-2 in rat placental tissue $(P<0.05)$. TMP treatment reduced miR-16-5p expression and elevated IGF-2 mRNA expression in agomir-16-5p-treated and sh-IGF-2-treated rats $(P<0.05)$ (Fig. 7A). Western blot assay showed that agomir-16-5p or sh-IGF-2 reduced IGF-2 protein expression in rat placental tissue $(P<0.05)$. TMP treatment can increase the expression of IGF-2 protein in agomir-16-5p-treated and sh-IGF-2-treated rats $(P<0.05)$ (Fig. 7B and C).

HE staining results showed that compared with agomir-NC or sh-NC, rats injected with lentiviral vector containing agomir-16-5p or sh-IGF-2 had swollen and thickened uterine decidua with obvious inflammatory cell infiltration, giant cell proliferation in the trophoblast of the placenta basal zone, increase in vacuole cells, and thickening of the baseband. Compared with agomir-
16-5p+DMSO or sh-IGF-2 + DMSO treatments, rats treated with agomir-16-5p+TMP or sh-IGF-2 + TMP had alleviation of the cysticity of the placental tissue, the degree of basal zone thickening, and the degree of inflammatory cell infiltration (Fig. 7D).

TEM observations showed that agomir-16-5p or sh-IGF-2 augmented autophagosome formation in rat placental tissue. TMP treatment suppressed autophagosome formation in rat placental tissue in agomir-16-5p-treated and sh-IGF-2-treated rats (Supplementary Fig. 1F).

Western blot assay showed that agomir-16-5p or sh-IGF-2 elevated the protein expression of LC3-II/LC3I, Beclin1, and SQSTM1, and diminished the protein expression of Ki67 in rat placental tissue $(P<0.05)$. TMP treatment reduced the protein expression of LC3-II/ LC3-I, Beclin1, and SQSTM1, and elevated the protein expression of Ki67 in rat placental tissue $(P<0.05)$ (Fig. 7E). These results indicate that TMP hinders the progression of $\mathrm{PE}$ in rats by regulating the miR-16-5p/ IGF-2 axis.

\section{Discussion}

$\mathrm{PE}$ is a frequently occurring disorder in pregnancy with some genetic inheritance, which is associated with maternal hypertension and proteinuria (Kaartokallio et al. 2016). Trophoblast cells are key regulators during the process of placental development,

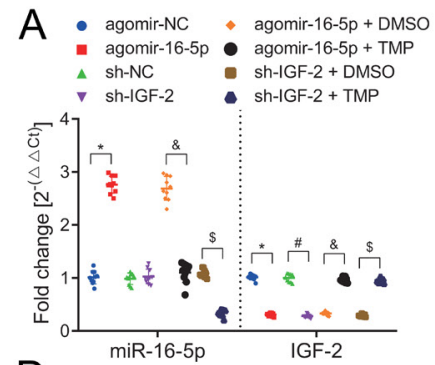

D

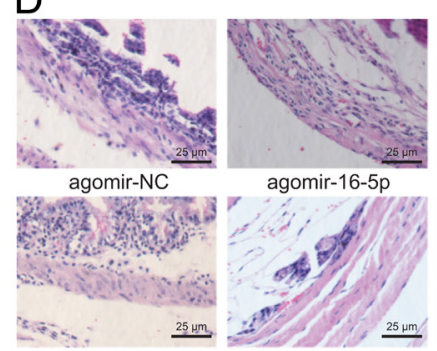

agomir-16-5p + DMSO agomir-16-5p + TMP
B

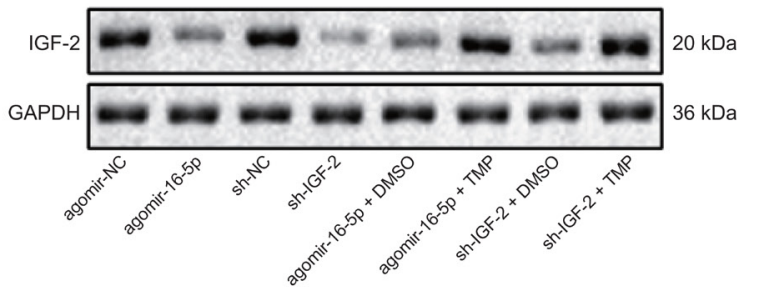

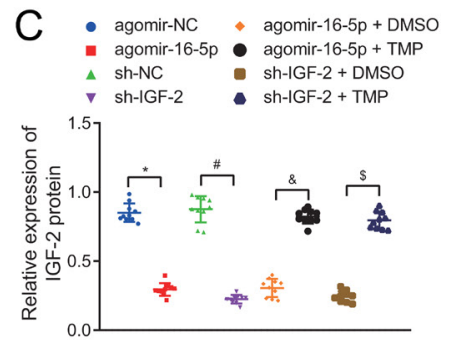

E

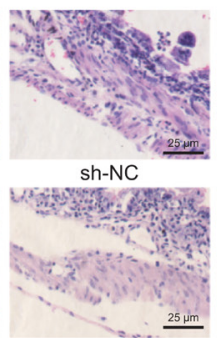

sh-IGF-2 + DMSO

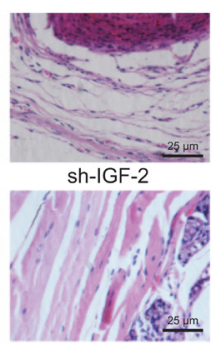

sh-IGF-2 + TMP
- agomir-16-5p - agomir-16-5p + TMP

$\Delta$ sh-NC sh-IGF-2 + DMSO

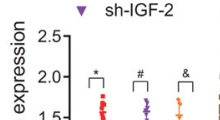
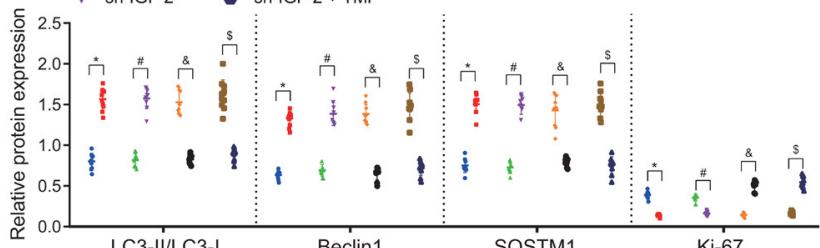

LC3-II/LC3-I

sh-IGF-2 + TMP
- agomir-NC agomir-16-5p + DMSO
Figure 7 TMP hinders the progression of PE in rats by regulating the miR-16-5p/IGF-2 axis. (A) qRT-PCR to detect miR-16-5p and IGF-2 expression in placental tissue in the presence of agomir-16-5p, sh-IGF-2 and TMP; (B and C) Western blot assay to detect IGF-2 protein expression in placental tissue in the presence of agomir-16-5p, sh-IGF-2 and TMP; (D) HE staining to detect pathological changes in placental tissue in the presence of agomir-16-5p, sh-IGF-2 and TMP (400x); (E) Western blot assay to detect LC3-II/LC3-I, Beclin1, SQSTM1 and Ki67 protein expression in placental tissue in the presence of agomir-16-5p, sh-IGF-2 and TMP; ${ }^{*} P<0.05$ vs agomir-NC group; $\# P<0.05$ vs sh-NC group; $\& P<0.05$ vs agomir-16-5p+DMSO group; $\$ P<0.05$ vs sh-IGF-2 + DMSO group. Measurement data are expressed as mean \pm S.D. Comparisons between groups were performed using one-way ANOVA with Tukey's post hoc test, $n=10$. 
and abnormal trophoblast cell activities are associated with pregnancy complications including PE (StraszewskiChavez et al. 2005). In China, physicians apply many TCMs, such as Uncaria rhynchophylla, in the treatment of PE and hypertension (Wang et al. 2018). Increased expression of certain miRNAs plays a critical role in modulating trophoblast behaviors, which may have potential as therapeutic biomarkers in PE (Niu et al. 2018). In this study, we clarified that TMP inhibits trophoblast cell autophagy and promotes trophoblast cell viability and migration in PE through regulating the miR-16-5p/lGF-2 axis (Fig. 8).

TMP, a purified and chemically identified component of a TCM, is an effective medicine to block vasoconstriction and to rescue damage from oxygen free radicals (Feng et al. 2004). After TMP treatment, the autophagosomes formed in trophoblast cells of PE rat placental tissues was appreciably diminished, and the expression of autophagy-related proteins LC3-II/ LC3-I, BECN1, and SQSTM was reduced, while the expression of proliferation-related protein Ki67 was elevated. These results indicate that TMP can impede the progression of PE in rats. To further explore the effect of TMP on autophagy of JEG3 cells, we performed Western blot analysis to detect the protein expression of autophagy-related genes LC3-II/LC3-I, Beclin 1 and SQSTM1. LC3 is also known as microtubuleassociated protein 1 light chain 3 (MAP1LC3), which is a homolog of Atg8 in mammals, including two mutually transformable forms, LC3-I and LC3-II involved in the formation of autophagosome membranes. Atg4 cleaves early synthesized pro-LC3 exposing C-terminal glycine to form a cytosolic soluble form of LC3-I. After induction of autophagy, LC3-I is coupled with the substrate PE on the surface of autophagosome membranes under the joint action of E1-like enzyme Atg7, E2-like enzyme Atg3 and E3-like enzyme Atg5Atg12-Atg16L complex to form a membrane-bound form of LC3-II. This LC3-II is an important marker molecule of autophagosome and accumulates with increasing abundance of autophagosome membranes. Beclin1 (BECN1), a homologous gene of yeast Atg6 in mammals, is phosphorylated by ULK1 and acts as an integral scaffold for the PI3K complex, promoting the localization of autophagic proteins to autophagic vacuoles. The autophagic system is substrate selective; the most widely used substrate for autophagic degradation is p62/SQSTM1, which can be coupled to microtubule-associated protein light chain 3, and participates as a regulator in the formation of autophagosomes, being degraded in the middle and late stages of autophagy (Glick et al. 2010, Pyo et al. 2012, Cicchini et al. 2015, Kuma et al. 2017). TMP was observed to ameliorate pregnancy-induced hypertension (Liu 1994). The application of TMP in hypertension syndrome of pregnancy has been highlighted to dilate blood vessel, to restore kidney function and to rescue microcirculatory function and rheology (Qian et al. 1991). Previous evidence has suggested that TMP can alleviate pulmonary pathological changes as well as systemic inflammatory reactions (Zhang \& Dang 2006). Moreover, our in vitro experiments also confirmed that TMP treatment can hinder the autophagy and augment viability and migration of human trophoblast cell line JEG3 concentration-responsively.

Recent studies have revealed the associations of miRNAs with the molecular mechanism in relation to TCM application (Dai et al. 2016, Liu et al. 2017). A prior study of human umbilical vein endothelial cells under hypoxic conditions has suggested that TMP augmented cell viability and repressed cell apoptosis through elevating miR-135b (Wei \& Wang 2019). Our observations have identified that miR-16-5p was upregulated in placental tissue of the PE rat model, and that TMP can repress the miR-16-5p expression in JEG3 cells. A similar study has uncovered that TMP can reduce cardiomyocyte apoptosis and restore their viability in ischemic heart disease through elevating miR-499a and diminishing its downstream target Sirt1 (Zhang et al. 2019a). The current study unveiled that

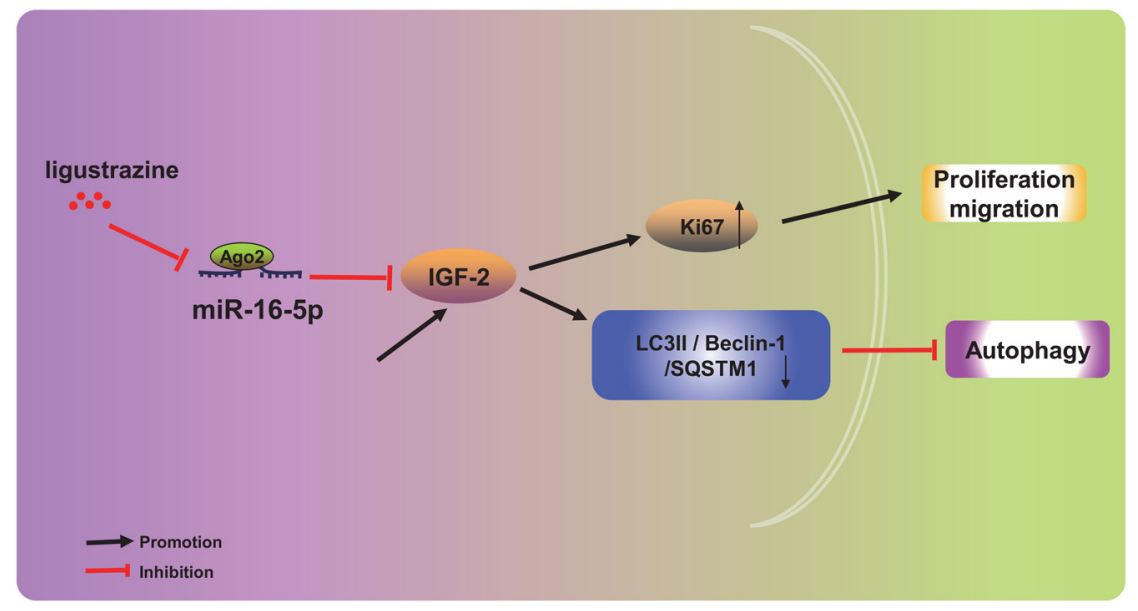

Figure 8 TMP inhibits trophoblast cell autophagy and promotes trophoblast cell viability and migration in $\mathrm{PE}$ through regulating the miR-16-5p/IGF-2 axis. In PE trophoblast cells, TMP may promote IGF-2 expression by inhibiting miR-16-5p. On the one hand, upregulated IGF-2 can inhibit the expression of LC3II/LC3I, Beclin-1, and SQSTM1, thereby inhibiting cell autophagy. On the other hand, upregulated IGF-2 can promote the expression of the proliferationrelated protein $\mathrm{Ki} 67$ protein, thereby promoting cell proliferation and migration. 
overexpression of miR-16-5p accelerated autophagy in JEG3 cells and restricted their viability and migration. Other evidence shows that miR-16 is associated with the anti-cancer effect of the TCM artesunate against bladder cancer through modulating proliferative behaviors of cancer cells (Zuo et al. 2014). Treatment with another TCM, Pien Tze Huang, upregulated miR-16 expression in hepatocellular carcinoma cells, which leads to repression of cancer cell growth (Qi et al. 2017). In severe PE, miR-16 was found to halt proliferation and migration of trophoblast cells through directly binding to cyclin E1 (Wang et al. 2012b).

In addition, our mechanistic investigations illuminated that miR-16-5p can target the IGF-2 gene and downregulate IGF-2 expression, thereby potentiating autophagy and abrogating viability and migration in JEG3 cells. The evidence presented by Chen et al. documented that miR-16 could bind to IGF1R and inversely modulated its expression, thereby exerting tumor suppressive activities in osteosarcoma (Chen et al. 2013). The importance of IGF-2 has been previously highlighted in the paracrine interplay at the maternal-fetal interface during pregnancy, which could affect trophoblast cell invasion in PE (Irwin et al. 1999). TMP administration was observed to function through triggering the activation of IGF1R survival signaling, which thereby halted the apoptosis of cardiomyocyte apoptosis under hypoxic conditions (Lin et al. 2015). Also, further exploration in the present study verified that TMP inhibited JEG3 cell autophagy and augmented cell viability and migration by regulating the miR-16-5p/ IGF-2 axis in vitro and in vivo.

Based on the present findings, we suggest that therapeutic strategies with TMP for PE should be directed toward the ablation of miR-16-5p, which may potentially be clinically viable targets in the treatment of PE. TMP inhibits trophoblast cell autophagy and promotes trophoblast cell viability and migration in PE through upregulating miR-16-5p and downregulating IGF-2. A better understanding of molecular mechanisms associated with the alleviatory effects of TMP in PE via miR-16-5p could enable the development of targeted therapies accompanied by TCM for pregnancy complications. Besides, existing literature has reported that PE patients are accompanied by liver dysfunction, such as increased alanine aminotransferase (ALT) and alkaline phosphatase (ALP) activity (Zhang et al. 2019b), but we did not detect the effect of TMP/miR-16-5p on liver function in rats in our experiment. We will explore the impairment of $\mathrm{TMP} / \mathrm{miR}-16-5 \mathrm{p}$ on liver function in future clinical experiments.

\section{Supplementary materials}

This is linked to the online version of the paper at https://doi. org/10.1530/REP-20-0309.

\section{Declaration of interest}

The authors declare that there is no conflict of interest that could be perceived as prejudicing the impartiality of the research reported.

\section{Funding}

This research did not receive any specific grant from any funding agency in the public, commercial or not-for-profit sector.

\section{Availability of data and materials}

The datasets generated and/or analyzed during the current study are available from the corresponding author on reasonable request.

\section{Author contribution statement}

Yuan Yuan conceived and designed research. Ling Zhao performed experiments and interpreted results of experiments. Xiaoying Wang analyzed data and prepared figures. Feng Lian drafted paper. Yan Cai edited and revised manuscript. All authors read and approved the final manuscript.

\section{Acknowledgement}

The authors would like to give our sincere appreciation to the reviewers for their helpful comments on this article.

\section{References}

Bozadjieva NI 2011 Insulin-like growth factors and placental ischemiainduced hypertension in the pregnant rat. Dissertations and Theses Gradworks.

Chen L, Wang Q, Wang GD, Wang HS, Huang Y, Liu XM \& Cai XH 2013 miR-16 inhibits cell proliferation by targeting IGF1R and the Raf1MEK1/2-ERK1/2 pathway in osteosarcoma. FEBS Letters 587 1366-1372. (https://doi.org/10.1016/j.febslet.2013.03.007)

Choi SY, Yun J, Lee OJ, Han HS, Yeo MK, Lee MA \& Suh KS 2013 MicroRNA expression profiles in placenta with severe preeclampsia using a PNAbased microarray. Placenta 34 799-804. (https://doi.org/10.1016/j. placenta.2013.06.006)

Cicchini M, Karantza V \& Xia B 2015 Molecular pathways: autophagy in cancer - a matter of timing and context. Clinical Cancer Research 21 498-504. (https://doi.org/10.1158/1078-0432.CCR-13-2438)

Dai GH, Liu N, Zhu JW, Yao J, Yang C, Ma PZ \& Song XB 2016 Qi-Shen-Yi-Qi dripping pills promote angiogenesis of ischemic cardiac microvascular endothelial cells by regulating microRNA-223-3p expression. EvidenceBased Complementary and Alternative Medicine 2016 5057328. (https:// doi.org/10.1155/2016/5057328)

Feng L, Xiong Y, Cheng F, Zhang L, Li S \& Li Y 2004 Effect of ligustrazine on ischemia-reperfusion injury in murine kidney. Transplantation Proceedings 36 1949-1951. (https://doi.org/10.1016/j. transproceed.2004.07.050)

Glick D, Barth S \& Macleod KF 2010 Autophagy: cellular and molecular mechanisms. Journal of Pathology 221 3-12. (https://doi.org/10.1002/ path.2697)

Gu S, Shen H, Zhou Y, Ni J, Zheng T, Mou Z \& Hua X 2019 Tetramethylpyrazine reduces the consequences of nitric oxide inhibition in pregnant rats. Journal of Cellular Physiology 234 19799-19806. (https://doi.org/10.1002/jcp.28579) 
Irwin JC, Suen LF, Martina NA, Mark SP \& Giudice LC 1999 Role of the IGF system in trophoblast invasion and pre-eclampsia. Human Reproduction 14 (Supplement 2) 90-96. (https://doi.org/10.1093/ humrep/14.suppl_2.90)

Jung YW, Shim JI, Shim SH, Shin YJ, Shim SH, Chang SW \& Cha DH 2019 Global gene expression analysis of cell-free RNA in amniotic fluid from women destined to develop preeclampsia. Medicine 98 e13971. (https:// doi.org/10.1097/MD.0000000000013971)

Kaartokallio T, Lokki Al, Peterson H, Kivinen K, Hiltunen L, Salmela E, Lappalainen T, Maanselka P, Heino S, Knuutila S et al. 2016 Preeclampsia does not share common risk alleles in 9p21 with coronary artery disease and type 2 diabetes. Annals of Medicine 48 330-336. (https://doi.org/10 .1080/07853890.2016.1174877)

Kuma A, Komatsu M \& Mizushima N 2017 Autophagy-monitoring and autophagy-deficient mice. Autophagy 13 1619-1628. (https://doi.org/10 .1080/15548627.2017.1343770)

Leach RE, Romero R, Kim YM, Chaiworapongsa T, Kilburn B, Das SK, Dey SK, Johnson A, Qureshi F, Jacques S et al. 2002 Pre-eclampsia and expression of heparin-binding EGF-like growth factor. Lancet 360 1215-1219. (https://doi.org/10.1016/S0140-6736(02)11283-9)

Li G, Ma L, Lin L, Wang YL \& Yang H 2018 The intervention effect of aspirin on a lipopolysaccharide-induced preeclampsia-like mouse model by inhibiting the nuclear factor-kappaB pathway. Biology of Reproduction 99 422-432. (https://doi.org/10.1093/biolre/ioy025)

Li Q, Zhang J, Su DM, Guan LN, Mu WH, Yu M, Ma X \& Yang RJ 2019 IncRNA TUG1 modulates proliferation, apoptosis, invasion, and angiogenesis via targeting miR-29b in trophoblast cells. Human Genomics 13 50. (https://doi.org/10.1186/s40246-019-0237-z)

Liang J, Li X, Kang C, Wang Y, Kulikoff XR, Coates MM, Ng M, Luo S, Mu Y, Wang X et al. 2019 Maternal mortality ratios in 2852 Chinese counties, 1996-2015, and achievement of millennium development goal 5 in China: a subnational analysis of the Global Burden of Disease Study 2016. Lancet 393 241-252. (https://doi.org/10.1016/S01406736(18)31712-4)

Lin KH, Kuo WW, Jiang AZ, Pai P, Lin JY, Chen WK, Day $\mathbf{C H}$, Shen CY, Padma VV \& Huang CY 2015 Tetramethylpyrazine ameliorated hypoxia-induced myocardial cell apoptosis via HIF-1alpha/JNK/p38 and IGFBP3/BNIP3 inhibition to upregulate PI3K/Akt survival signaling. Cellular Physiology and Biochemistry 36 334-344. (https://doi. org/10.1159/000374076)

Liu SY, Xu YY \& Zhu JY 1994 The effects of Salvia miltiorrhizae Bge and ligustrazine on thromboxane A2 and prostacyclin in pregnancy induced hypertension. Zhonghua Fu Chan Ke Za Zhi 29 648-650, 697.

Liu Y, Wang M, Luo Y, Chen J, Lu Y, Shi Y, Tang C, Zhou Q, Zhang H, Hu Y et al. 2017 MiRNA-target network analysis identifies potential biomarkers for Traditional Chinese Medicine (TCM) syndrome development evaluation in hepatitis B caused liver cirrhosis. Scientific Reports 7 11054. (https://doi.org/10.1038/s41598-017-11351-5)

Maccani MA, Padbury JF \& Marsit CJ 2011 miR-16 and miR-21 expression in the placenta is associated with fetal growth. PLOS ONE 6 e21210. (https://doi.org/10.1371/journal.pone.0021210)

Niu ZR, Han T, Sun XL, Luan LX, Gou WL \& Zhu XM 2018 MicroRNA$30 a-3 p$ is overexpressed in the placentas of patients with preeclampsia and affects trophoblast invasion and apoptosis by its effects on IGF-1. American Journal of Obstetrics and Gynecology 218 249.e1-249.e12. (https://doi.org/10.1016/j.ajog.2017.11.568)

Phillips RA, Ma Z, Kong B \& Gao L 2020 Maternal hypertension, advanced Doppler haemodynamics and therapeutic precision: principles and illustrative cases. Current Hypertension Reports 22 49. (https://doi. org/10.1007/s11906-020-01060-2)

Pyo JO, Nah J \& Jung YK 2012 Molecules and their functions in autophagy. Experimental and Molecular Medicine 44 73-80. (https://doi. org/10.3858/emm.2012.44.2.029)

Qi F, Zhou S, Li L, Wei L, Shen A, Liu L, Wang Y \& Peng J 2017 Pien Tze Huang inhibits the growth of hepatocellular carcinoma cells by upregulating miR-16 expression. Oncology Letters 14 8132-8137. (https://doi.org/10.3892/ol.2017.7240)

Qian XH, Huang YL \& Wu SP 1991 Treatment of hypertension syndrome of pregnancy with ligustrazine. Zhong Xi Yi Jie He Za Zhi 11 533-534, 516.

Rana S, Lemoine E, Granger JP \& Karumanchi SA 2019 Preeclampsia: pathophysiology, challenges, and perspectives. Circulation Research 124 1094-1112. (https://doi.org/10.1161/CIRCRESAHA.118.313276)
Redman CW \& Sargent IL 2005 Latest advances in understanding preeclampsia. Science 308 1592-1594. (https://doi.org/10.1126/ science.1111726)

Rozas-Villanueva MF, Casanello P \& Retamal MA 2020 Role of ROS/RNS in preeclampsia: are connexins the missing piece? International Journal of Molecular Sciences 21 4698. (https://doi.org/10.3390/ijms21134698)

Say L, Chou D, Gemmill A, Tuncalp Ö, Moller AB, Daniels J, Gulmezoglu AM, Temmerman M \& Alkema L 2014 Global causes of maternal death: a WHO systematic analysis. Lancet: Global Health 2 e323-e333. (https://doi.org/10.1016/S2214-109X(14)70227-X)

Straszewski-Chavez SL, Abrahams VM \& Mor G 2005 The role of apoptosis in the regulation of trophoblast survival and differentiation during pregnancy. Endocrine Reviews 26 877-897. (https://doi.org/10.1210/er.2005-0003)

Vento-Tormo R, Efremova M, Botting RA, Turco MY, Vento-Tormo M, Meyer KB, Park JE, Stephenson E, Polanski K, Goncalves A et al. 2018 Single-cell reconstruction of the early maternal-fetal interface in humans. Nature 563 347-353. (https://doi.org/10.1038/s41586-018-0698-6)

Wang XF \& Zhao MQ 2003 Ligustrazine and Salvia miltiorrhiza injection solution in complementary therapy of pregnancy-induced hypertension: clinical analysis of 60 cases. Di Yi Jun Yi Da Xue Xue Bao 23 969-971.

Wang W, Feng L, Zhang H, Hachy S, Satohisa S, Laurent LC, Parast M, Zheng J \& Chen DB 2012a Preeclampsia up-regulates angiogenesisassociated microRNA (i.e., miR-17, -20a, and -20b) that target ephrin-B2 and EPHB4 in human placenta. Journal of Clinical Endocrinology and Metabolism 97 E1051-E1059. (https://doi.org/10.1210/jc.2011-3131)

Wang Y, Fan H, Zhao G, Liu D, Du L, Wang Z, Hu Y \& Hou Y $2012 b$ miR-16 inhibits the proliferation and angiogenesis-regulating potential of mesenchymal stem cells in severe pre-eclampsia. FEBS Journal 279 4510-4524. (https://doi.org/10.1111/febs.12037)

Wang YL, Dong PP, Liang JH, Li N, Sun CP, Tian XG, Huo XK, Zhang BJ, Ma XC \& Lv CZ 2018 Phytochemical constituents from Uncaria rhynchophylla in human carboxylesterase 2 inhibition: kinetics and interaction mechanism merged with docking simulations. Phytomedicine 51 120-127. (https://doi.org/10.1016/j.phymed.2018.10.006)

Wei S \& Wang H 2019 Ligustrazine promoted hypoxia-treated cell growth by upregulation of miR-135b in human umbilical vein endothelial cells. Experimental and Molecular Pathology 106 102-108. (https://doi. org/10.1016/j.yexmp.2018.12.005)

Yang X, Yang Y, Yuan Y, Liu L \& Meng T 2020 The roles of uterine natural killer (NK) cells and KIR/HLA-C combination in the development of preeclampsia: a systematic review. BioMed Research International 2020 4808072. (https://doi.org/10.1155/2020/4808072)

Zhang JX \& Dang SC 2006 Ligustrazine alleviates acute lung injury in a rat model of acute necrotizing pancreatitis. Hepatobiliary and Pancreatic Diseases International 5 605-609.

Zhang X, Dong H, Liu Y, Han J, Tang S \& Si J 2019a Tetramethylpyrazine partially relieves hypoxia-caused damage of cardiomyocytes H9c2 by downregulation of miR-449a. Journal of Cellular Physiology 2341 5098-15107. (https://doi.org/10.1002/jcp.28151)

Zhang WM, Cao P, Xin L, Zhang Y, Liu Z, Yao N \& Ma YY $2019 b$ Effect of miR-133 on apoptosis of trophoblasts in human placenta tissues via Rho/ROCK signaling pathway. European Review for Medical and Pharmacological Sciences 23 10600-10608. (https://doi.org/10.26355/ eurrev_201912_19755)

Zhou X, Geng L, Wang D, Yi H, Talmon G \& Wang J 2017 R-Spondin1/LGR5 activates TGFbeta signaling and suppresses colon cancer metastasis. Cancer Research 77 6589-6602. (https://doi.org/10.1158/0008-5472. CAN-17-0219)

Zuo W, Wang ZZ \& Xue J 2014 Artesunate induces apoptosis of bladder cancer cells by miR-16 regulation of COX-2 expression. International Journal of Molecular Sciences 15 14298-14312. (https://doi.org/10.3390/ ijms150814298)

Received 3 June 2020

First decision 29 June 2020

Revised Manuscript received 14 September 2020

Accepted 17 September 2020 